\title{
Anemia de diamond-blackfan
}

\section{Diamond-blackfan anemia}

Pág. 63,68

Recibido: 22-05-2020

Aceptado: 02-09-2020

Dra. Sofía Gallo Durán ${ }^{1}$

Dra. Alina Castillo Jiménez ${ }^{2}$

Dra. Gloriana Villalobos Alvarado ${ }^{3}$

1,2,3. Médico general, investigador independiente, San José, Costa Rica.

\section{RESUMEN}

La anemia de Diamond-Blackfan es una enfermedad infrecuente, congénita, autosómica dominante, en la que el defecto principal es la mutación en una proteína ribosomal. Se caracteriza por una aplasia eritroide que da como resultado una anemia macrocítica normocrómica de inicio en la infancia y asocia malformaciones congénitas y susceptibilidad a padecer malignidades. El diagnóstico está basado en factores clínicos y moleculares. El tratamiento inicial son transfusiones sanguíneas y corticoesteriodes; pero en la actualidad, el único tratamiento curativo conocido es el trasplante alogénico de células madre, hematopoyéticas de un donador compatible.

\section{PALABRAS CLAVE}

Anemia Aplasica, Anemia de Diamond-Blackfan, Médula Ósea, Enfermedades Genéticas Congénitas, Anomalías Congénitas

\section{ABSTRACT}

Diamond-Blackfan anemia is a rare, congenital, autosomal dominant disease in which the main defect is a mutation in a ribosomal protein. It is characterized by erythroid aplasia that results in normochromic macrocytic anemia, this disease begins in childhood and associates congenital malformations and susceptibility to malignancies. The diagnosis is based on clinical and molecular features. The initial treatment is blood transfusions and corticosteroids; but currently the only known curative treatment is allogeneic hematopoietic stem cell transplantation from a compatible donor.

\section{KEY WORDS}

Anemia, Aplastic, Anemia, Diamond-Blackfan, Bone Marrow, Genetic Diseases, Inborn, Congenital Abnormalities 


\section{INTRODUCCIÓN}

La anemia de Diamond-Blackfan (ADB) también llamada anemia hipoplásica congénita, es una enfermedad congénita caracterizada por una aplasia celular asociada a anormalidades de la medula ósea, malformaciones congénitas y predisposición para desarrollar malignidades. $(1,2,3)$. Es una enfermedad rara, autosómica dominante en su mayoría, pero también puede ser esporádica (4). Está causada por una serie de mutaciones y deleciones en genes de proteínas ribosomales (5).

La mayoría de los individuos con este padecimiento suelen presentar síntomas en el transcurso del primer año de vida, sin embargo, los síntomas se pueden presentar en cualquier momento de la vida (6). El síntoma principal es la anemia macrocítica normocrómica, con reticulocitopenia, disminución del recuento de glóbulos blancos y una aplasia eritroide $(7,8)$. Además de la anemia y las anormalidades de la médula ósea, se asocian malformaciones congénitas (6). No obstante, en la actualidad es cada vez mayor el número de casos que no cumple los criterios clínicos (7).

La enfermedad fue descrita por primera vez en 1936, sin embargo, fue hasta 1938 que los doctores Louis Diamond y Kenneth Blackfan describieron el síndrome de anemia hipoplásica (1). Inicialmente, era clasificada como una enfermedad inmunológica y, fue hasta 1999, que se descubrió que era una enfermedad genética, específicamente un problema en una proteína de los ribosomas $(2,3)$. En el 2005 , fue la primera enfermedad que se relacionó con una función alterada del ribosoma y, fue la primera clasificada como ribosomopatia $(3,9)$.

La revisión bibliográfica tiene como objetivo recopilar información y evidencia actual sobre la definición, el diagnóstico y el tratamiento de la anemia de Diamond-Blackfan con el fin de utilizar la evidencia clínica para diagnosticar precozmente la enfermedad y tratarla de la mejor manera.

\section{MÉTODO}

Para la elaboracion de la siguiente revisión bibliográfica, se utiliza la búsqueda avanzada en PUBMED, UptoDate, Google Scholar, Cochrane Library, Scielo, Jaypee Digital, MEDLINE, Clinical Key, Scopus, EBSCO, Ovid, como bases de datos para información electrónica. Durante la investigación se indaga en publicaciones sobre diagnóstico y manejo de la anemia de Diamond-Blackfan, siendo estos los resultados seleccionados al ingresar palabras claves, tales como: Anemia Hipoplásica Congénita, Anemia de Diamond-Blackfan, Médula Ósea, Enfermedades Genéticas Congénitas, Anomalías Congénitas. Al realizar la búsqueda se utiliza los siguientes criterios de inclusión: publicaciones entre el 2016-2020, en idioma inglés. Posteriormente se realiza un proceso de exclusión para los artículos no relacionados con pacientes con Anemia de Diamond-Blackfan. Al finalizar el proceso, se selecciona un total de 15 artículos; con lo que se procedió a una recopilación, revisión y organización bibliográfica para la realización del artículo.

\section{DEFINICIÓN}

La ADB es una enfermedad genética, autosómica dominante (10); donde todas las mutaciones de proteínas ribosomales halladas actualmente son heterocigotos, las homocigotas son incompatibles con la vida (9). Es un tipo de anemia infrecuente, caracterizada 
por ser macrocítica, sin otras características de anemia megaloblástica, y normocrómica, que usualmente es diagnosticada en la infancia temprana $(10,11)$. Además delaanemia, presenta un cuadro clínico de insuficiencia o ausencia de precursores de glóbulos rojos en una médula ósea por lo demás sana (10), reticulocitopenia, retraso del crecimiento y aumento de la adenosina desaminasa de los eritrocitos $(6,11)$. Puede presentar malformaciones congénitas, que son más frecuentes en la zona de la cabeza, cuello, corazón, extremidades superiores y sistema urinario $(6,11)$. Las malformaciones se presentan en aproximadamente el $50 \%$ de los pacientes (1), algunas de ellas están ligadas a una mutación en una proteína ribosomal especifica (2). Los pacientes con ADB tienen mayor riesgo de desarrollar malignidad, tanto de origen sólido o hematológico (11).

\section{EPIDEMIOLOGÍA}

La $A D B$ es una enfermedad muy infrecuente, tiene una incidencia de 1-4 casos por cada 50000 recién nacidos vivos. Ambos sexos se ven afectados por igual y no se ha identificado ninguna predisposición étnica $(4,12)$. Aproximadamente el $90 \%$ de los pacientes son diagnosticados en el primer año de vida, y un $35 \%$ es diagnosticado en el primer mes de vida (13).

\section{DIAGNÓSTICO}

La ADB se debe sospechar en lactantes pequeños (en el primer año de vida), que presenten malformaciones congénitas, palidez, falla para progresar y que se documente anemia severa con reticulocitopenia $(13,15)$. Existen unos criterios diagnósticos (tabla 1) los cuales deben estar todos presentes, y de no estarlo, existen criterios de soporte que ayudan al diagnóstico $(12,13)$.

\section{CRITERIOS DIAGNÓSTICOS}

1. Anemia macrocítica normocrómica en el primer año de vida

2. Reticulocitopenia

3. Médula ósea normo celular con deficiencia selectiva de precursores eritroides

4. Conteo leucocitario normal o ligeramente disminuido

5. Conteo plaquetario normal o ligeramente aumentado

\section{CRITERIOS DE SOPORTE MAYOR}

1. Mutación genética clásica de ADB

2. Antecedente heredo familiar positivo

\section{CRITERIOS DE SOPORTE MENOR}

1. Hemoglobina fetal elevada

2. Anomalías congénitas

3. Actividad elevada de la adenosina desaminasa de los eritrocitos

4. Sin evidencia de otro síndrome de insuficiencia de médula ósea

Bibliografía $(12,13,14)$ 
El diagnóstico es probable si se cumple uno de los siguientes: todos los criterios diagnósticos están presentes; tres criterios diagnósticos más un criterio de soporte mayor; dos criterios diagnósticos y tres criterios de soporte menor; un criterio de soporte mayor y tres criterios de soporte menor (13).

Posterior al diagnóstico clínico, se debe tomar muestra de sangre que incluya estudio de recuento sanguíneo completo y reticulocitario. Se debe tomar biopsia de médula ósea y estudios moleculares (15). Además, es necesario descartar una infección por Parvovirus B19 mediante serologías (4).

Imagen 1. Frotis de sangre periférica de un paciente con $\mathrm{ADB}$ (16)

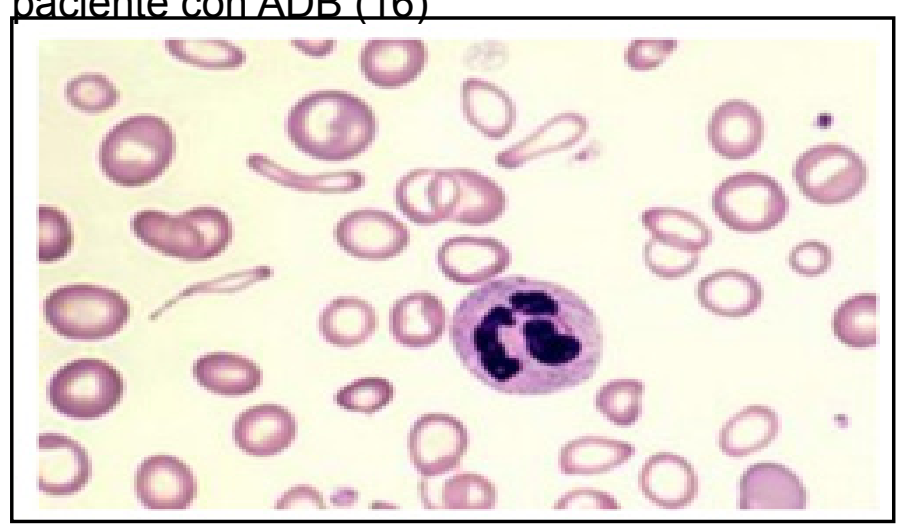

Imagen tomada de revista scielo (http://scielo.sld. cu/pdf/rpr/v21n4/rpr16417.pdf).

\section{DIAGNÓSTICO MOLECULAR}

Para el diagnóstico molecular, el primer paso es evaluar la médula ósea y caracterizar el fenotipo de la enfermedad (4). La mayoría de las lesiones genéticas en la $A D B$ involucran genes que codifican proteínas ribosómicas $(12,15)$. En un $25 \%$ de los casos, la mutación se encuentra en el gen RPS19, sin embargo, se han identificado al menos 12 genes implicados, donde la mayoría codifican proteínas ribosomales (5). La segunda lesión más común son las grandes deleciones $(15-20 \%)$, las cuales se han identificado en más de 20 genes $(9,14,15)$. El objetivo inicial es identificar defectos genéticos utilizando técnicas disponibles y comunes como la secuenciación de Sanger y/o el array de hibridación genómica comparativa. Si no se identifica ninguna mutación con estas técnicas, lo siguiente por hacer es la secuenciación del exoma, con el fin de encontrar otra mutación implicada $(9,14,15)$. En un $30 \%$ $35 \%$ de los pacientes no se demuestra ninguna mutación $(7,5)$.

\section{DIAGNÓSTICO DIFERENCIAL}

Es importante hacer el diagnóstico diferencial con enfermedades que presentan deficiencia de la médula ósea. La eritroblastopenia transitoria de la infancia, la anemia hipoplásica severa y la anemia diseritropoyética congénita son parte del diagnóstico diferencial. El parvovirus B19 $y$ algunas otras infecciones virales, pueden presentar deficiencia de la médula ósea $(13,14)$.

\section{TRATAMIENTO}

La piedra angular del tratamiento de la ADB son los corticoides y las transfusiones sanguíneas. Aproximadamente un $20 \%$ de los niños con esta patología logran la recuperación de manera espontánea luego del tratamiento inicial (11).

Las transfusiones sanguíneas se inician al diagnóstico y se mantienen hasta que los niños cumplen 6-12 meses de edad. Posteriormente, se inicia el tratamiento con corticoesteroides (es eficaz en el $80 \%$ de los pacientes) con prednisona o prednisolona a dosis de $2 \mathrm{mg} / \mathrm{kg} / \mathrm{día}$ $(8,10,14)$. Una vez que la hemoglobina empieza a aumentar (usualmente a las 4-6 semanas) se disminuyen los esteroides paulatinamente hasta 
lograr la mínima dosis eficaz que mantenga la hemoglobina $\geq 9 \mathrm{~g} / \mathrm{dL}$. Es necesario hacer chequeos periódicos para identificar efectos secundarios de los corticoides $(10,13)$.

Los pacientes que no responden al tratamiento con esteroides y/o que presentan intolerancia a este, van a requerir transfusiones sanguíneas a repetición. Estos pacientes tienen mayor riesgo de presentar hemosiderosis por transfusión, por lo que requieren chequeos rutinarios. El trasplante de células madre hematopoyéticas de un donante HLA (antígenos leucocitarios humanos) compatible es curativo y se puede utilizar en los pacientes que no responden al tratamiento convencional. Sin embargo, este procedimiento tiene muchos efectos secundarios, por lo que su uso sigue en estudio $(8,10)$.

\section{CONCLUSIÓN}

La anemia de Diamond-Blackfan es una enfermedad heterogénea, congénita, autosómica dominante, que se acompaña de anemia hipoplásica, malformaciones congénitas y predisposición a enfermedades malignas. A pesar de ser una patología poco frecuente, presenta un reto en la medicina actual, debido al componente genético que constantemente se encuentra en estudio, además de la complejidad que presenta para hacer el diagnóstico. Por lo que es de suma importancia reconocer y sospechar las manifestaciones clínicas, para diagnosticarla a tiempo y tratarla. Los esteroides y las transfusiones sanguíneas son la primera línea de tratamiento y han demostrado una efectividad alta, sin embargo, no son curativos. El único tratamiento curativo es el trasplante de células hematopoyéticas de un donador HLA compatible. El tratamiento de primera línea ha logrado que la mortalidad de esta enfermedad sea baja. Sin embargo, no se ha logrado disminuir la predisposición a malignidades que tienen los pacientes, y que es la principal causa de muerte. Es importante, una vez diagnosticada la $A D B$, lograr un manejo interdisciplinario para

1. Noel C. Diamond-Blackfan anemia RPL35A: a case report. Journal of Medical Case Reports. 2019;13(1).

2. van Dooijeweert $B$, van Ommen C, Smiers F, Tamminga $R$, te Loo M, Donker A et al. Pediatric Diamond-Blackfan anemia in the Netherlands: An overview of clinical characteristics and underlying molecular defects. European Journal of Haematology. 2017;100(2):163-170.

3. Sakamoto K, Narla A. Perspective on Diamond-Blackfan anemia: lessons from a rare congenital bone marrow failure syndrome. Leukemia. 2017;32(2):249-251.

4. Gadhiya K, Budh DP. Diamond Blackfan Anemia. [Updated 2019 Nov 23]. In: StatPearls [Internet]. Treasure Island (FL): StatPearls Publishing; 2020 Jan.

5. Arbiv O, Cuvelier G, Klaassen R, Fernandez C, Robitaille N, Steele M et al. Molecular analysis and genotype-phenotype correlation of Diamond-Blackfan anemia. Clinical Genetics. 2017;93(2):320328.

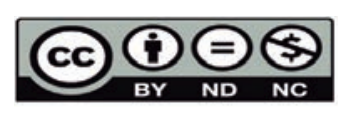


6. Li H, Lodish H, Sieff C. Critical Issues in Diamond-Blackfan Anemia and Prospects for Novel Treatment. Hematology/Oncology Clinics of North America. 2018;32(4):701-712.

7. Ulirsch et al., The Genetic Landscape of Diamond-Blackfan Anemia, The American Journal of Human Ge- netics (2018), https://doi.org/10.1016/j.ajhg.2018.10.027

8. Khan S. UpToDate [Internet]. Uptodate.com. 2019 [cited 13 April 2020]. Available from: https:// www.uptodate.com/contents/hematopoietic-cell-transplantation-for-diamond-blackfan-anemiaand-the-myelodysplastic-syndromes-in-children-and-adolescents?search=anemia\%20diamond\%20blackfan\&source=search_result\&selectedTitle=1 25\&usage_type=default\&display_ rank=1.

9. Da Costa L, Narla A, Mohandas N. An update on the pathogenesis and diagnosis of DiamondBlackfan anemia. F1000Research. 2018;7:1350.

10. Kliegman R, Stanton B, St. Geme J, Schor N, Behrman R, Nelson W. Nelson textbook of pediatrics. 20th ed. Canada: ELSEVIER; 2016.

11. Aspesi A, Borsotti C, Follenzi A. Emerging Therapeutic Approaches for Diamond Blackfan Anemia. Current Gene Therapy. 2018;18(6):327-335.

12. Engidaye G, Melku M, Enawgaw B. Diamond Blackfan Anemia: genetics, pathogenesis, diagnosis and treatment. The journal of the international Federation of Clinical Chemistry and Laboratory Medicine. 2019;30:67-81.

13. Sandoval C. UpToDate [Internet]. Uptodate.com. 2020 [cited 15 April 2020]. Available from: https://www.uptodate.com/contents/anemia-in-children-due-to-decreased-red-blood-cellproduction? search=anemia $\% 20$ diamond $\% 20$ blackfan $\% 20$ sandoval\&source $=$ search result\&selectedTitle=2 25\&usage_type=default\&display_rank=2

14. Bartels M, Bierings M. How I manage children with Diamond-Blackfan anaemia. British Journal of Haematology. 2018;184(2):123-133.

15. L. Da Costa, Marie.-Franç. O'Donohue, B. van Dooijeweert, et al., Molecular approaches to diagnose Diamond-Blackfan anemia: The EuroDBA experience, European Journal of Medical Genetics (2017), doi: 10.1016/j.ejmg.2017.10.017.

16. Viñas Díaz O, Valdés Sojo C, Alvarez Reinoso S. Anemia de Blackfan Diamond [Internet]. Scielo.sld.cu. 2017 [cited 23 August 2020]. Available from: http://scielo.sld.cu/pdf/rpr/v21n4/ rpr16417.pdf 